Clinical Nutrition

\title{
A novel approach to assess body composition in children with obesity from density of the fat-free mass \\ --Manuscript Draft--
}

\begin{tabular}{|c|c|}
\hline Manuscript Number: & YCLNU-D-20-00419R3 \\
\hline Article Type: & Full Length Article \\
\hline Keywords: & $\begin{array}{l}\text { body composition; fat free mass; density; Children; obesity; air displacement } \\
\text { plethysmography }\end{array}$ \\
\hline Corresponding Author: & $\begin{array}{l}\text { Veronica Luque, Dr } \\
\text { Universitat Rovira i Virgili } \\
\text { Reus, SPAIN }\end{array}$ \\
\hline First Author: & Desirée Gutiérrez-Marín \\
\hline \multirow[t]{18}{*}{ Order of Authors: } & Desirée Gutiérrez-Marín \\
\hline & Joaquin Escribano \\
\hline & Ricardo Closa-Monasterolo \\
\hline & Natalia Ferré \\
\hline & Michelle Venables \\
\hline & Priya Singh \\
\hline & Jonathan CK Wells \\
\hline & Judit Muñoz-Hernando \\
\hline & Marta Zaragoza-Jordana \\
\hline & Mariona Gispert-Llauradó \\
\hline & Carme Rubio-Torrents \\
\hline & Mireia Alcázar \\
\hline & Mercè Núñez-Roig \\
\hline & Raquel Monné-Gelonch \\
\hline & Albert Feliu \\
\hline & Josep Maria Basora \\
\hline & Ana Maria Alejos \\
\hline & Veronica Luque, Dr \\
\hline Abstract: & $\begin{array}{l}\text { Background \& Aims: Assessment of Fat Mass (FM) and fat free mass (FFM) using Air- } \\
\text { displacement plethysmography (ADP) technique assumes constant density of FFM } \\
\text { (DFFM) by age and sex. It has been recently shown that DFFM further varies } \\
\text { according to body mass index (BMI), meaning that ADP body composition } \\
\text { assessments of children with obesity could be biased if DFFM is assumed to be } \\
\text { constant. The aim of this study was to validate the use of the calculations of DFFM } \\
\text { (rather than constant density of the FFM) to improve accuracy of body composition } \\
\text { assessment in children with obesity. Methods: cross-sectional validation study in } 66 \\
\text { children with obesity (aged } 8 \text { to } 14 \text { years) where ADP assessments of body } \\
\text { composition assuming constant density (FFMBODPOD and FMBODPOD) were } \\
\text { compared to those where DFFM was adjusted in relation to BMI (FFMadjusted and } \\
\text { FMadjusted), and both compared to the gold standard reference, the } 4 \text {-component } \\
\text { model (FFM4C and FM4C). Results: FFMBODPOD was overestimated by } 1.50 \mathrm{~kg} \\
\text { (95\%Cl }-0.68 \mathrm{~kg}, 3.63 \mathrm{~kg} \text { ) while FFMadjusted was } 0.71 \mathrm{~kg}(-1.08 \mathrm{~kg}, 2.51 \mathrm{~kg}) \\
\text { (percentage differences compared to FFM4C were } 4.9 \%( \pm 2.9 \%) \text { and } 2.8 \%( \pm 2.1 \%) \text {, } \\
\text { respectively ( }<<0.001) \text { ). Consistently, FM was underestimated by both methods, } \\
\text { representing a mean difference between methods of } 4.0 \%( \pm 2.9 \%) \text { and } 6.8 \%( \pm 3.8 \%) \text {, }\end{array}$ \\
\hline
\end{tabular}


respectively, when compared to the reference method. The agreement and reliability of body composition assessments were improved when adjusted using calculations (adjusted models) rather than assuming constant DFFM. Conclusions: The use of constant values for fat-free mass properties may increase bias when assessing body composition (FM and FFM) in children with obesity by two-component techniques such as ADP. Using adjusted corrections as proposed in the present work may reduce the bias by half. 


\section{A novel approach to assess body composition in children with

4 AUTHORSHIP: Desirée Gutiérrez-Marín a , Joaquin Escribano ${ }^{a, b}$, Ricardo Closa-Monasterolo ${ }^{a, c}$,

5 Natalia Ferréa, Michelle Venables ${ }^{d}$, Priya Singh ${ }^{d}$, Jonathan CK Wellse, Judit Muñoz-Hernando ${ }^{a}$,

6 Marta Zaragoza-Jordanaa , Mariona Gispert-Llauradóa, Carme Rubio-Torrentsa, Mireia Alcázara

7 Mercè Núñez-Roiga, Raquel Monné-Gelonch ${ }^{f}$, Albert Feliub $^{b}$, Josep Maria Basora ${ }^{f}$, Ana M Alejos ${ }^{g}$,

8 Veronica Luque ${ }^{\mathrm{a}, \mathrm{h}}$.

a Paediatric Nutrition and Human Development Research Unit, Universitat Rovira i Virgili, IISPV. Address: C/ Sant Llorenç 21, 43201 Spain

b Hospital Universitari Sant Joan de Reus. Address: Av. del Dr. Josep Laporte, 2, 43204 Reus, Spain

c Hospital Universitari de Tarragona Joan XXIII. Address: C/Dr. Mallafré Guasch 4, 43005 Tarragona, Spain

d Stable Isotope Laboratory, NIHR BRC Nutritional Biomarker Laboratory and Wellcome Trust-MRC Institute of Metabolic Science, University of Cambridge, Cambridge, UK

e Childhood Nutrition Research Centre, UCL Great Ormond Street Institute of Child Health. Address: 30 Guilford St, Holborn, London WC1N 1EH, London, UK

f Unitat de Suport a la Recerca Tarragona-Reus, IDIAPJGol. Address: Camí de Riudoms 53-55, 43204 Reus, Spain

g Hospital Lleuger de Cambrils. Address: Plaça de I'Ajuntament, 2-3, 43850 Cambrils, Spain

h Serra Hunter Fellow

22 Corresponding author:

23 Veronica Luque

24 Paediatric Nutrition and Human Development Research Unit

25 C/ Sant Llorenç 21

$26 \quad 43201$ Reus

27 Veronica.luque@urv.cat

28 Tel. 0034977759365 


\section{ABSTRACT}

32 Background \& Aims: Assessment of Fat Mass (FM) and fat free mass (FFM) using Air-

33 displacement plethysmography (ADP) technique assumes constant density of FFM ( $D_{F F M}$ ) by age

34 and sex. It has been recently shown that $D_{F F M}$ further varies according to body mass index (BMI),

35 meaning that ADP body composition assessments of children with obesity could be biased if $D_{F F M}$

36 is assumed to be constant. The aim of this study was to validate the use of the calculations of

$37 \mathrm{D}_{\mathrm{FFM}}$ (rather than constant density of the FFM) to improve accuracy of body composition

38 assessment in children with obesity. Methods: cross-sectional validation study in 66 children

39 with obesity (aged 8 to 14 years) where ADP assessments of body composition assuming

40 constant density (FFM

41 relation to $\mathrm{BMI}$ (FFM adjusted $_{\text {and }}$ and $\mathrm{FM}_{\text {adjusted }}$ ), and both compared to the gold standard reference,

42 the 4-component model $\left(\mathrm{FFM}_{4 \mathrm{C}}\right.$ and $\mathrm{FM}_{4 \mathrm{C}}$ ). Results: $\mathrm{FFM}_{\mathrm{BODPOD}}$ was overestimated by $1.50 \mathrm{~kg}$

$43(95 \% \mathrm{Cl}-0.68 \mathrm{~kg}, 3.63 \mathrm{~kg})$ while $\mathrm{FFM}_{\text {adjusted }}$ was $0.71 \mathrm{~kg}(-1.08 \mathrm{~kg}, 2.51 \mathrm{~kg})$ (percentage differences

44 compared to $\mathrm{FFM}_{4 \mathrm{c}}$ were $4.9 \%( \pm 2.9 \%)$ and $2.8 \%( \pm 2.1 \%)$, respectively $\left.(\mathrm{p}<0.001)\right)$. Consistently,

45 FM was underestimated by both methods, representing a mean difference between methods of

$464.0 \%( \pm 2.9 \%)$ and $6.8 \%( \pm 3.8 \%)$, respectively, when compared to the reference method. The

47 agreement and reliability of body composition assessments were improved when adjusted using

48 calculations (adjusted models) rather than assuming constant $D_{\mathrm{FFM}}$. Conclusions: The use of

49 constant values for fat-free mass properties may increase bias when assessing body composition

50 (FM and FFM) in children with obesity by two-component techniques such as ADP. Using

51 adjusted corrections as proposed in the present work may reduce the bias by half. 


\section{INTRODUCTION}

54 Many health and disease conditions are related to body composition status and changes therein,

55 both in adults and children (1). For this reason, important applications of body composition

56 assessment include the diagnosis of disease, monitoring clinical progress and tailoring 57 treatment.

58 Body mass index (BMI) is widely considered as the accepted clinical standard to classify

59 nutritional status; it is commonly used as the screening tool for overweight and obesity and has

60 been recommended for this purpose by the World Health Organization (WHO) due to it being

61 inexpensive, simple and fast to carry out (2). BMI represents the ratio of body weight to height-

62 squared; however, it cannot distinguish between body weight components, namely the fat-free

63 mass (FFM) and fat mass (FM). In addition, BMI does not have a constant association with body

64 composition across the range of age, sex or ethnicity (3), and this can lead to misclassification of

65 nutritional status.

66 The gold standard method to assess body composition in vivo is the 4-component (4C) model,

67 which divides body weight into fat, protein, mineral and water. To perform this analysis, several

68 individual 2-component techniques are needed: air-displacement plethysmography (ADP) to

69 obtain body volume (BV); dual-energy X-ray absorptiometry (DXA) to obtain bone mineral

70 content (BMC); and isotopic dilution with deuterium (DD) to obtain total body water (TBW).

71 Commonly, to simplify the protocol, these techniques are often used in isolation to assess body

72 composition. However, this practice requires the use of several assumptions such as the

73 assumption of constant FFM properties (density and hydration) (8). These assumptions can

74 introduce a degree of bias in body composition assessment due to different physiological and

75 pathological factors (9), including age (10), sex, ethnicity, hormone cycle, pregnancy, fasting,

76 nutritional status (11-13), kidney or gastrointestinal diseases, etc. In fact, the current methods

77 available have greater error in those with obesity, and this error tends to increase with obesity 78 level (14).

79 ADP studies in adults have concluded that the individual variation in FFM properties such as 80 hydration and density could influence the accuracy of body composition results $(15,16)$. ADP has 81 been validated to assess body composition in children with relatively high precision $(17,18)$. 82 However, a study comparing ADP with a 3-component model concluded that ADP showed high 83 precision at group level, but indicated that biological individual characteristics such as hydration 84 could increase bias at the individual level (17). The standard approach in densitometric methods 85 such as ADP is to calculate body composition assuming that values for the density of fat mass 
86 (FM) and FFM are constant by age and sex (19). Recently, it has been shown in children that the 87 hydration of FFM increases, and the density of FFM decreases, with the degree of obesity (12).

88 This study reported a predictive equation to estimate the density and hydration of FFM, which

89 could be used when using a 2-component model to assess children and adolescents with 90 different degrees of obesity. Our hypothesis is that calculating the density of the FFM adjusted 91 in this way for BMI as well s age and sex (12), rather than using a constant value by age and sex,, 92 may improve the body composition analyses in subjects with obesity.

93 The aim of this study was to validate the use of FFM density calculations in body composition 94 assessmentsby air-displacement plethysmography (ADP) against the 4-component model to 95 improve the accuracy and precision of the body composition predictions in children and 96 adolescents with obesity.

\section{MATERIALS and METHODS}

98

99

100

101

102

103

104

105

106

107

108

109

110

\section{Design}

This is a cross-sectional validation study, secondary to a clustered randomized clinical trial on a motivational intervention to treat children with obesity. To perform the present validation study, we used the baseline body composition data of the participants enrolled in the OBEMAT2.0 clinical trial (20).

\section{Participants}

Data from 66 children with obesity ( 35 males; 31 females) aged 8 to 14 years were obtained from the clinical trial OBEMAT2.0 at baseline. Children were recruited from June 2016 to March 2018 from primary healthcare centres belonging to the "Camp de Tarragona" healthcare area. Obesity was categorised according to $\mathrm{BMI}$ values $\geq 97^{\text {th }}$ percentile of the Hernández references from 1988 (21) defined by the national Guidelines for Clinical Practice on the Prevention and Treatment of Childhood and Adolescent Obesity (22). At recruitment, patients were excluded from the motivational intervention if they had known eating disorders according to the primary care paediatrician (such as bulimia), were participating in another randomized clinical trial, were receiving corticoid or ADHD treatment, or presented with neuropathies and/or endocrinopathies (Cushing Syndrome, Prader Willi Syndrome, hypothyroidism, etc. previously 


\section{Body composition analyses}

118 Examinations were taken between 8:00 a.m. and 10:00 a.m. after an overnight fast. The physical 119 examination consisted of basic anthropometric measurements: weight (HT), height (HT) and 120 body mass index (BMI); and body composition assessment using: DXA which was performed by 121 a specialist trained technician using a General Electric (GE) Lunar Prodigy Advance (Madison, Wi, 122 USA) with GE, Axial Lunar Prodigy Full Advance (encore 2014 version 15.20.002) software to 123 obtain BMC; ADP with a BOD POD ${ }^{\circledR}$ device (COSMED, Life Measurements, Inc, Concord, CA) to 124 obtain BV, FM BODPOD and FFM BODPOD; and DD analysis where the participants had an oral dose 125 equivalent to $1 \mathrm{~g} / \mathrm{kg}$ body weight of deuterium oxide $\left(\mathrm{D}_{2} \mathrm{O}, 99.8 \%\right.$, CK Isotopes Ltd., Ibstock, 126 Leicestershire, UK). Urine samples collected over the following 5 days were analysed by isotope 127 ratio mass spectrometry (Sercon ABCA-Hydra 20-22, Sercon Ltd, Crewe, Cheshire, UK) to obtain 128 TBW with a precision of $0.94 \mathrm{~L}$. Further, FM and FFM were calculated by the $4 \mathrm{C}$ model using the 129 equation of Fuller (1992) (23):

$$
\mathrm{FM}_{4 C}=(2.747 \times \mathrm{BV})-(0.710 \times \mathrm{TBW})+(1.460 \times \mathrm{BMC})-(2.050 \mathrm{XWT})
$$

131 where $\mathrm{FM}=$ fat mass in $\mathrm{kg} ; \mathrm{BV}=$ body volume (L) from $\mathrm{ADP} ; \mathrm{TBW}=$ total body water volume (L) 132 from deuterium dilution; $\mathrm{BMC}=$ bone mineral content $(\mathrm{kg})$ from $\mathrm{DXA}$ and $\mathrm{WT}=$ body weight $(\mathrm{kg})$. $133 \mathrm{FFM}_{4 \mathrm{C}}$ was then calculated as the difference of FM from body weight, in $\mathrm{kg}$.

135 Body composition measures from ADP ( $F M_{B O D P O D}$ and FFM 136 the FFM ( $D_{\mathrm{FFM}}$ )was compared to body composition measures based on predicted density of the 137 FFM (FMadjusted and FFM adjusted) and both compared to the gold standard reference 4C model $138\left(\mathrm{FM}_{4 \mathrm{c}}\right.$ and $\left.\mathrm{FFM}_{4 \mathrm{c}}\right)$.

139

140 Steps for the calculation of adjusted measures of body composition from Air Displacement 141 Plethysmography

142 Derived values for the density of fat-free mass $\left(D_{F F M}\right)$ were used with an assumed constant 143 density of fat mass to generate age specific constants ( $C 1$ and $\mathrm{C2}$ ), which are needed in the 144 generic Siri equation (24) to calculate the percentage of body fat (\%BF) as follows.

\section{Density of the fat-free mass (predicted)}

Density of the FFM ( $D_{F F M}$ ) was calculated using the following predictive equation (12):

$$
D_{F F M}=1.0791+(0.009 \times \text { age })+(0.0021 \times \text { gender })-(0.0014 \times \text { BMISDS })
$$


148 where age is in years; gender $1=$ male and $2=$ female; BMISDS $=$ body mass index in z-score.

2. C1 and C2 were calculated as (25):

150

$$
\begin{aligned}
& C 1=\frac{\left(D_{F F M} \times D_{F M}\right)}{\left(D_{F F M}-D_{F M}\right)} \\
& C 2=\frac{\left(D_{F M}\right)}{\left(D_{F F M}-D_{F M}\right)}
\end{aligned}
$$

152 where $D_{F M}=0.9007 \mathrm{~kg} / \mathrm{L}$ (assumed constant) and $D_{F F M}$ was predicted in the previous step.

153

154 3. Percentage of body fat (\%BF) calculated using the generic Siri equation (24):

$$
\% \mathrm{BF}=\left(\frac{\mathrm{C} 1}{\mathrm{BD}}-\mathrm{C} 2\right) \times 100
$$

156 where $\mathrm{BD}=$ body density, and was calculated as:

$$
\mathrm{BD}=\frac{\mathrm{WT}}{\mathrm{BV}}
$$

158 where BV = body volume in L, obtained from the BOD POD output.

159

4. Calculation of $\mathrm{FM}_{\text {adjusted }}$ and $\mathrm{FFM}_{\text {adjusted: }}$

$161 \mathrm{FM}(\mathrm{kg})$ derived from the density of FFM and ADP body volume measurements (FM $\left.{ }_{\text {adjusted }}\right)$ was 162 further calculated as:

$$
F M_{\text {adjusted }}=\frac{\% \mathrm{BF} \times \mathrm{WT}}{100}
$$

164 where WT = body weight in $\mathrm{kg}$.

165 Then, $\mathrm{FFM}_{\text {adjusted }}$ was calculated as the difference of FMadjusted from body weight, in $\mathrm{kg}$.

167 Statistical analysis

168 All statistical analyses were performed using IBM SPSS Statistics for Windows (version 25.0; IBM 169 Corp., Armonk, NY, USA). Descriptive characteristics for the overall sample (weight, height, BMI, 170 BMI SDS, body volume, total body water, FFM density and FM and FFM from the different 171 methods used) are shown as Mean \pm Standard Deviation (SD). The Kolmogorov-Smirnov test for 172 normality was applied to assess the distribution of the variables. Differences between boys and 173 girls in anthropometric and body composition parameters were explored using Student's T-test 
174 or Mann Whitney U-Test, depending on the distribution. The degree of difference between 175 techniques was given as mean percentage with limits of agreement calculated as \pm 2 standard 176 deviations of the bias. We assessed the linear association between FFM and FM measurements 177 from BodPod output ( FM $_{\text {BODPOD }}$ and FFM $_{\text {BODPOD) }}$ and calculations derived from the predicted

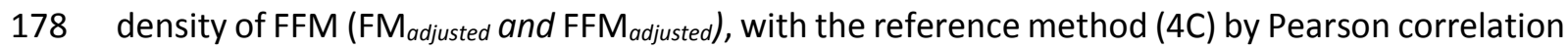
179 coefficients. Reliability was obtained from Cronbach's $\alpha$ analysis. Concordance was given as the 180 intraclass correlation coefficient (ICC) with a confidence interval (CI) of 95\%. Bland and Altman 181 plots were performed to assess agreement between methods and bias trends, and the limits of 182 agreement for FM and FFM against the reference method (4C) were calculated.

\section{Ethics}

185 The study followed the rules of the Declaration of Helsinki (26). Ethical committees of all 186 involved study centres (CEIC Hospital Universitari de Tarragona Joan XXIII, CEIC Hospital 187 Universitari Sant Joan de Reus (29 ${ }^{\text {th }}$ January 2016, code 16-01-28/1ass2), CEIC IDIAP Jordi Gol 188 (26 ${ }^{\text {th }}$ November 2015, code PI14/116)) approved the protocol. All parents or legal guardians 189 signed informed consent prior to study enrolment. Children aged 12 years or above also gave 190 written informed assent.

\section{RESULTS}

193 Physical characteristics of the participants are shown in Table 1. Children were of white 194 European ancestry, with an average age of $10.7 \pm 1.5$ y (8 to 13.3 years) and BMI SDS ranging 195 from 1.86 to 3.08 SDS. We only found statistically significant differences between males and 196 females in BMI SDS $(p=0.038)$ and $D_{F F M}(p<0.001)$.

197 Differences between FFM $_{\text {adjusted }}$ and FFM 198 method (FFM 4 ) (Figure 1). FFM adjusted was slightly overestimated by $0.71 \mathrm{~kg}$ (limits of agreement $199-1.08 \mathrm{~kg}, 2.51 \mathrm{~kg}$ ) showing a mean difference of $2.8 \% \pm 2.1 \% \mathrm{p}<0.001)$. FFM BODPOD was 200 overestimated by $1.50 \mathrm{~kg}$ (limits of agreement $-0.68 \mathrm{~kg}, 3.63 \mathrm{~kg}$ ), showing a two-fold percentage 201 of difference when compared to $4 \mathrm{C}(4.9 \% \pm 2.9 \%$; $p<0.001)$ than $\mathrm{FFM}_{\text {adjusted. }}$.

202 Consistently, FM was underestimated by both methods, FMadjusted by $-0.71 \mathrm{~kg}$ (limits of 203 agreement $1.1 \mathrm{~kg},-2.5 \mathrm{~kg}$ ) and $\mathrm{FM}_{\text {BODPOD }}-1.4 \mathrm{~kg}$ (limits of agreement $0.9 \mathrm{~kg},-3.6 \mathrm{~kg}$ ) representing a 204 mean difference of $4.0 \% \pm 2.9 \%$ and $6.8 \% \pm 3.8 \%$, respectively, when compared to the reference 205 method (FM 4 ) (Figure 1) (Table 2). This meant that the degree of bias from the method 
206 following adjustment for density of FFM (FM adjusted $_{\text {) }}$ ) was two-fold lower than the FM BODPOD 207 (consistently with FFM measures).

209 Table 3 displays the correlations and reliability coefficients of both techniques, showing that 210 when body composition measurements were adjusted for FFM density, the concordance and 211 reliability of the assessment were improved as compared to the gold standard method.

\section{DISCUSSION}

214 The aim of the present study was to assess the accuracy of body composition assessment in 215 patients with obesity using ADP, following a correction for FFM density compared to not 216 following the correction. To assess the accuracy of both methods, we used the gold standard 217 method to assess body composition in vivo, the 4-component model. To our knowledge, this is 218 the first study to include individual calculations for the density of fat-free mass when assessing 219 body composition using ADP, and to then compare the results with the 4-component model in 220 children with obesity.

221 Children with obesity may have a significantly lower density of FFM than normal weight children 222 (12), however, the BOD POD internal algorithms assume constant values of FFM density by age 223 and sex. Our study has demonstrated that this assumption may increase the degree of bias when 224 assessing body composition in children with obesity.

225 Previously published data has suggested that assumptions of the properties of FFM could be the 226 cause of bias in the evaluation of $\operatorname{FM}$ by $\operatorname{ADP}(15,17)$. However, there are few studies which have 227 used a multi-compartment model to compare ADP measurements, and furthermore, most of 228 the previous studies were conducted in adults.

229 In a study of 42 healthy British females, Fields et al. (15) reported that, compared to the $4 C$ 230 model, body fat percentage measured using BOD POD calculations was underestimated, 231 although both techniques were well correlated. They also investigated the relative hydration of 232 FFM as a possible explanation for such differences and found that indeed the hydration of FFM 233 was associated with the magnitude of the difference between the techniques.

234 In agreement with Fields et al., Millard-Stafford et al. (16) conducted a similar study in 50 young, 235 healthy adults of varying ethnicity (males $n=40$ : Caucasians $n=35$; African-Americans $n=15$ ) 236 and found that \%FM obtained from BOD POD was underestimated when compared to the $4 C$ 237 model and other methods such as under water weighing (UW) or DXA. They concluded that FFM 
238 density and its fractional components (i.e. minerals, water and protein), were important 239 considerations when determining FM and FFM. These findings are consistent with the findings 240 of our present study in children.

241 To our knowledge, the only existing study comparing BodPod ADP and other techniques with 242 the $4 \mathrm{C}$ model was conducted by Fields and Goran (27) with 25 healthy British children. They did 243 not find significant bias between ADP and 4C, but no BMI data was included in their analysis. 244 Furthermore, the sample was homogenous in age (11.4 $\pm 1.4 \mathrm{y})$ and anthropometric characteristics.

246 Wells et al. (17) evaluated 28 British healthy children aged 5 to 7 years using ADP and compared 247 it to the $3 \mathrm{C}$ model. They found high accuracy of ADP when compared to the $3 \mathrm{C}$ model for body 248 composition measurements in groups but highlighted the need to improve bias in individuals. 249 They concluded that the bias between methods could be due to methodological precision or 250 biological variability in hydration. In addition, according to an earlier finding, Wells et al. (8) 251 reported that the calculated density of FFM was slightly increased for both sexes, but 252 significantly so only for girls, when compared to Lohman's 1989 reference data. Thus, they 253 showed significant bias in \%FM compared to the $3 \mathrm{C}$ model when using predicted values for the 254 density of FFM. This implies that BOD POD calculations should be adjusted by specific FFM 255 properties to increase its accuracy. A recent publication from a large dataset compiled from 256 several UK studies confirmed that FFM hydration and density varied according to age and BMI 257 (12). In the present study we have shown how to apply this recent knowledge to increase the 258 accuracy of more simple techniques to assess body composition in children with obesity.

259 The results of our work are consistent with those previously presented by Wells et al (8). FM and 260 FFM assessment had a narrower agreement with 4C model measurements when calculations 261 were adjusted by specific FFM density than BOD POD outputs, which did not consider the 262 nutritional status of the subjects and assumed a constant density of FFM. Thus, this study 263 demonstrates and validates the use of corrections of FFM for density when using BOD POD. As 264 the 4-component model is not usually feasible in clinical settings nor in big epidemiology studies, 265 ADP correcting for FFM properties might be one of the best 2-component models in children, 266 especially in children with obesity. The translation of the present results to a clinical setting could 267 be easily done by simple calculations as shown in steps 1 to 4 in the methods section. First, 268 calculating the predicted density of $D_{\mathrm{FFM}}$ according to BMI $\mathrm{z}$ scores; second, using the predicted $269 D_{\mathrm{FFM}}$ values in the $\mathrm{C} 1$ and $\mathrm{C} 2$ equations (rather than using constant values) and third, using those $270 \mathrm{C} 1$ and C2 values in the customized version of Siri's equation, together with body density 271 (derived from body volume provided by the ADP device), to estimate body fat percentage. To 
272 facilitate calculations, we provide an excel file with all the steps as supplementary online 273 material.

274 In addition, using these adjustments would lalso improve the longitudinal assessment of 275 patients with obesity; if the degree of error for the Bod Pod outputs ranged 4.1 to $7.5 \%$ for FM 276 and FFM, these biases could be greater than real changes between visits in a follow up. If this 277 bias could be minimized to 2.3 to $4.7 \%$ by applying the proposed corrections, this would improve 278 the sensibility of the method to changes in energy balance and improve clinical assessment.

279 The small sample size is a possible limitation of the present study; however, it remains one of 280 the biggest sample sizes published for this type of analysis in children.

281 The main strength of the present study is the high quality of the methodology used: we used a 282 highly precise technique to assess body composition, and compared it to the gold standard 4283 component model in order to reduce the bias of ADP in children with obesity. In addition, the 284 conditions of the measurements were highly controlled as all the measurements being performed at the same time between 8 and 10:00 a.m. after an overnight fast.

286 In conclusion, the use of constant values for fat-free mass properties may increase bias when 287 assessing body composition in children with obesity using two-component based techniques like 288 air-displacement plethysmography. Using corrections for the density of fat-free mass (as 289 proposed with the 4 steps in the methodology section) reduces the bias in fat mass and fat-free 290 mass measurements derived from ADP in children with obesity. This approach should be 291 considered not only in children with obesity. Further studies should demonstrate whether this 292 approach would improve assessments in the general population and in longitudinal studies 293 where small changes between repeated measures should be quantified with reduced bias.

ACKNOWLEDGMENTS: We gratefully acknowledge the participating families, the dedication of 296 the healthcare centre professionals, the nurses of the endocrinology department and the 297 members of the Institut de Diagnòstic per la Imatge de l'Hospital Universitari de Tarragona Joan 298 XXIII; the nurses supporting the project and the members at Diagnòstic per la Imatge de 299 I'Hospital Universitari Sant Joan de Reus; and the IISPV BioBanc Team. We thank the Stable 300 Isotope Facility, MRC Elsie Widdowson Laboratory, Cambridge, UK for the analysis of the 301 samples used in the calculation of total body water by deuterium dilution.

302 Obemat2.0 Study Group: Closa-Monasterolo R, Feliu-Rovira A, Escribano J, Ferré N, Luque V, Zaragoza303 Jordana M, Gispert-Llauradó M, Rubio-Torrents MC, Gutiérrez-Marín D, Muñoz-Hernando J, Núñez-Roig 304 M, Alcázar M, Sentís S, Esteve M (Pediatric Nutrition and Human Development Research Unit, Universitat 
Rovira i Virgili, IISPV, Reus). Monné-Gelonch R, Basora JM, Flores G, Hsu P, Rey-Reñones C, Alegret C (IDIAP Jordi Gol i Gurina, USR Reus); Guillen N, Alegret-Basora C, Ferre R (Hospital Universitari Sant Joan de Reus); Arasa F (Hospital Verge de la Cinta de Tortosa, Institut Català de la Salut); Alejos AM, Diéguez M, Serrano MA, Mallafré M, González-Hidalgo R, Braviz L, Resa A, Palacios M, Sabaté A, Simón L (Hospital Lleuger de Cambrils, Sagessa); Losilla AC, De La Torre S, Rosell L, Adell N, Pérez C, Tudela-Valls C, CaroGarduño R, Salvadó O, Pedraza A, Conchillo J, Morillo S (CAP Llibretat, Reus, Institut Català de la Salut); Garcia S, Mur EM, Paixà S, Tolós S, Martín R, Aguado FJ, Cabedo JL, Quezada LG (CAP Marià Fortuny, Reus, Sagessa); Domingo M, Ortega M, Garcia RM, Romero O, Pérez M, Fernández M, Villalobos ME (CAP Salou, Institut Català de la Salut); Ricomà G, Capell E, Bosch M, Donado A, Sanchis FJ, Boix A, Goñi X, Castilla E, Pinedo MM, Supersaxco L, Ferré M, Contreras J (CAP Rambla Nova, Institut Català de la Salut, Tarragona); Sanz-Manrique N, Lara A, Rodríguez M, Pineda T, Segura S, Vidal S, Salvat M (CAP Les Borges del Camp-Montroig del Camp, Institut Català de la Salut); Mimbrero G, Albareda A, Guardia J, Gil S, Lopez M (CAP Sant Pere, Reus, Institut Català de la Salut); Ruiz-Escusol S, Gallardo S (CAP Bonavista-La Canonja, Tarragona, Institut Català de la Salut); Machado P, Bocanegra R (CAP Torreforta-La Granja, Tarragona, Institut Català de la Salut); Espejo T, Vendrell M (ABS Vandellòs-L'Hospitalet de l'Infant, Sagessa); Solé C, Urbano R, Vázquez MT, Fernández-Antuña L (CAP Muralles, Tarragona); Barrio M, Baudoin A, González N (CAP El Morell, Institut Català de la Salut); Olivé R, Lara RM, Dinu C, Vidal C (CAP Sant Pere i Sant Pau, Tarragona, Institut Català de la Salut); González S, Ruiz-Morcillo E, Ainsa ME, Vilalta P, Aranda B (CAP Sant Salvador, Tarragona, Institut Català de la Salut); Boada A, Balcells E (ABS Alt Camp Est, Vilarodona, Institut Català de la Salut);

Statement of Authorship: DG, VL and JW contributed to build the scientific hypothesis; DG and $\mathrm{VL}$ had main role in drafting the article; JE, RC, NF, RM and JB directed coordinated and supervised the overall project; MV and PS performed isotopic analyses; DG, JM, MZ, MG, CR, $\mathrm{MA}, \mathrm{MN}$ and $\mathrm{AA}$ collected data; all the authors revised the manuscript and agreed with the content.

Conflict of interests: The authors declare no conflicts of interest.

Funding: The project OBEMAT2.0 clinical trial received funding of the Ministry of Economy and Competitiveness of the Spanish Government ("Proyectos de Investigación en Salud") Reference PI15/00970 and PI15/01411. The funding source had no role in the design of this study and will have no role during its execution, analyses, interpretation of the data or in any decision to submit results. 
1. Wells JCK, Fewtrell MS. Is body composition important for paediatricians? Arch Dis Child. 2008;93(2):168-72.

2. Nishida C, Barba C, Cavalli-Sforza T. Appropriate body-mass index for Asian populations and its implications for policy and intervention strategies WHO. Lancet (London, England). 2004;363:157-63.

3. Wells JCK. A Hattori chart analysis of body mass index in infants and children. Int J Obes Relat Metab Disord. 2000;24(3):325-9.

4. Pietrobelli A, Faith MS, Allison DB, Gallagher D, Chiumello G, Heymsfield SB. Body mass index as a measure of adiposity among children and adolescents: A validation study. J Pediatr. 1998;132(2):204-10.

5. Vanderwall C, Randall Clark R, Eickhoff J, Carrel AL. BMI is a poor predictor of adiposity in young overweight and obese children. BMC Pediatr. 2017;17(1):135.

6. Romero-Corral A, Somers VK, Sierra-Johnson J, Thomas RJ, Collazo-Clavell ML, Korinek J, et al. Accuracy of body mass index in diagnosing obesity in the adult general population. Int J Obes. 2008;32(6):959-66.

7. Ode JJ, Pivarnik JM, Reeves MJ, Knous JL. Body mass index as a predictor of percent fat in college athletes and nonathletes. Med Sci Sports Exerc. 2007;39(3):403-9.

8. Wells JCK, Fuller NJ, Dewit O, Fewtrell MS, Elia M, Cole TJ. Four-component model of body composition in children: Density and hydration of fat-free mass and comparison with simpler models. Am J Clin Nutr. 1999;69(5):904-12.

9. Brozek J, Grande F, Anderson JT, Keys A. Densitometric analysis of body composition: revision of some quantitative assumptions. Ann New York Acad Sci. 1963;110:113-40.

10. Lohman TG. Assessment of Body Composition in Children. Pediatr Exerc Sci. 1989;1:1930 .

11. Haroun D, Wells JCK, Williams JE, Fuller NJ, Fewtrell MS, Lawson MS. Composition of the fat-free mass in obese and nonobese children: Matched case-control analyses. Int J Obes. 2005;29(1):29-36.

12. Gutiérrez-Marín D, Luque V, Ferré N, Fewtrell MS, Williams JE, Wells JCK. Associations of age and body mass index with hydration and density of fat-free mass from 4 to 22 years. Eur J Clin Nutr. 2019;

13. Wells JCK, Fewtrell MS, Williams JE, Haroun D, Lawson MS, Cole TJ. Body composition in normal weight, overweight and obese children: matched case-control analyses of total and regional tissue masses, and body composition trends in relation to relative weight. Int J Obes (Lond). 2006;30(10):1506-13.

14. Luque V, Closa-Monasterolo R, Rubio-Torrents C, Zaragoza-Jordana M, Ferré N, GispertLlauradó $\mathrm{M}$, et al. Bioimpedance in 7-year-old children: validation by dual X-ray absorptiometry - part 1: assessment of whole body composition. Ann Nutr Metab. 2014;64(2):113-21.

15. Fields DA, Wilson GD, Gladden LB, Hunter GR, Pascoe DD, Goran MI. Comparison of the BOD POD with the four-compartment model in adult females. Med Sci Sports Exerc. 2001;33(9):1605-10. 
16. Millard-Stafford ML, Collins MA, Evans EM, Snow TK, Cureton KJ, Rosskopf LB. Use of air displacement plethysmography for estimating body fat in a four-component model. Med Sci Sports Exerc. 2001;33(8):1311-7.

17. Wells JCK, Fuller NJ, Wright A, Fewtrell MS, Cole TJ. Evaluation of air-displacement plethysmography in children aged 5-7 years using a three-component model of body composition. Br J Nutr. 2003;90(03):699.

18. Fields DA, Hunter GR, Coran MI. Validation of the BOD POD with hydrostatic weighing: Influence of body clothing. Int J Obes. 2000;24(2):200-5.

19. Wells JCK, Fewtrell MS. Measuring body composition. Arch Dis Child. 2006;91(7):612-7.

20. Luque V, Feliu A, Escribano J, Ferré N, Flores G, Monné R, et al. The Obemat2.0 Study: A Clinical Trial of a Motivational Intervention for Childhood Obesity Treatment. Nutrients. 2019;11(2):419.

21. Hernandez M, Castellet J, Narvaíza JL, Rincón JM, Ruiz I, Sánchez E, et al. Curvas y tablas de crecimiento. Instituto de Investigación sobre Crecimiento y Desarrollo. Fundación Orbegozo. (Growth charts and tables (1988). Growth and Development Research Institute. Orbegozo Foundation.). Ergon, editor. Bilbao; 1988. p. 125, 133.

22. Spanish Ministry of Science and Innovation. Guía de Práctica Clínica sobre prenvencion y el tratamineto de la obesidad infantojuvenil. London, UK: Centro Cochrane Iberoamericano; 2009.

23. Fuller NJ, Jebb S a, Laskey $\mathrm{M}$ a, Coward $\mathrm{W}$ a, Elia $\mathrm{M}$. Four-component model for the assessment of body composition in humans: comparison with alternative methods, and evaluation of the density and hydration of fat-free mass. Clin Sci. 1992;82(6):687-93.

24. Siri W. Body composition from fluid spaces and density: analysis of methods. In: Brozek J, Henschel A, editors. Techniques for measuring body compositon. Washingt Natl Acad Sci - Natl Res Counc. 1961;223-244.

25. Wells JCK, Williams JE, Chomtho S, Darch T, Grijalva-Eternod C, Kennedy K, et al. Pediatric reference data for lean tissue properties: Density and hydration from age 5 to 20 y. Am J Clin Nutr. 2010;91(3):610-8.

26. World Medical Association. WMA Declaration of Helsinki - Ethical principles for Medical research involving human subjects 2013.

27. Fields $\mathrm{D}$ a, Goran MI. Body composition techniques and the four-compartment model in children. J Appl Physiol. 2000;89(2):613-20. 
415 Table 1. Descriptive characteristics of the participants.

\begin{tabular}{|c|c|c|c|c|}
\hline & \multicolumn{2}{|c|}{ Male $(n=35)$} & \multicolumn{2}{|c|}{ Female $(n=31)$} \\
\hline & Mean $\pm S D$ & Range & Mean $\pm S D$ & Range \\
\hline Age (y) & $10.6 \pm 1.6$ & $8.0-13.3$ & $10.7 \pm 1.4$ & $8.3-13.3$ \\
\hline Weight (kg) & $55.1 \pm 11.2$ & $37.8-83.1$ & $57.5 \pm 11.4$ & $37-81.8$ \\
\hline Height (cm) & $146.4 \pm 10.0$ & $131.6-167.0$ & $147.2 \pm 10.7$ & $125.5-170.3$ \\
\hline $\mathrm{BMI}\left(\mathrm{kg} / \mathrm{m}^{2}\right)$ & $25.6 \pm 2.60$ & $21.7-32.5$ & $26.2 \pm 2.4$ & $21.9-30.6$ \\
\hline BMI SDS (WHO 2007) $)^{+}$ & $2.72 \pm 0.45$ & $1.86-4.20$ & $2.52 \pm 0.31$ & $1.89-3.08$ \\
\hline Body Volume (BodPod - L) & $54.8 \pm 11.3$ & $37.5-83.7$ & $57.4 \pm 11.2$ & $36.1-81.1$ \\
\hline Density FFM predicted $(\mathrm{kg} / \mathrm{L})^{\ddagger}$ & $1.087 \pm 0.002$ & $1.083-1.091$ & $1.089 \pm 0.001$ & $1.087-1.092$ \\
\hline FM D\&BV $(k g)$ & $21.6 \pm 5.9$ & $13.0-38.2$ & $23.8 \pm 5.2$ & 11.- -32.1 \\
\hline$F F M_{D \& B V}(k g)$ & $33.5 \pm 6.1$ & $23.7-46.2$ & $33.7 \pm 7.8$ & $20.2-53.7$ \\
\hline FM & $21.3 \pm 6.0$ & $12.7-38.4$ & $22.7 \pm 5.0$ & $11.4-30.4$ \\
\hline FFM BODPOD $(\mathrm{kg})$ & $34.0 \pm 5.9$ & $24.1-46.2$ & $34.8 \pm 7.5$ & $21.2-51.9$ \\
\hline $\mathrm{FM}_{4 \mathrm{C}}(\mathrm{kg})$ & $22.1 \pm 6.0$ & $12.5-38.7$ & $24.7 \pm 5.3$ & $11.6-33.8$ \\
\hline $\mathrm{FFM}_{4 \mathrm{C}}(\mathrm{kg})$ & $33.0 \pm 6.1$ & $23.5-45.6$ & $32.8 \pm 7.4$ & $20.3-50.6$ \\
\hline Total Body Water (DD-kg) & $25.0 \pm 4.6$ & $17.9-34.9$ & $24.3 \pm 5.3$ & $15.7-36.5$ \\
\hline
\end{tabular}

416 Significance: ${ }^{\dagger} p=0.038 ;{ }^{\ddagger} p<0.001$.

417 Abbreviations: $\mathrm{BMI}=$ body mass index; $\mathrm{SDS}=$ standard deviation score; $\mathrm{FM}=$ fat mass; $F \mathrm{FM}=$ fat 418 free mass; $D \& B V=$ measurements derived from the density of FFM calculated with the new 419 equation and body volume; $4 \mathrm{C}=$ four-component model; $\mathrm{DD}=$ deuterium dilution. 
421 Table 2. Analyses of differences (\%) between body composition outcomes extracted from the

422 BodPod (adjusted using calculated values for the density of fat free mass) versus the reference 423 4-component model $(n=66)$.

\begin{tabular}{llc}
\hline & MEAN DIFFERENCE & SD \\
& (max, min 95\% Cl; p-value) & \\
\hline FFM $_{\text {adjusted }}$ & $2.80 \%(2.29-3.30 ; p<0.001)$ & $\pm 2.06 \%$ \\
FM $_{\text {adjusted }}$ & $3.97 \%(3.25-4.69 ; p<0.001)$ & $\pm 2.92 \%$ \\
\hline FFM $_{\text {BODPOD }}$ & $4.87 \%(4.15-5.59 ; p<0.001)$ & $\pm 2.92 \%$ \\
& & \\
\hline FM $_{\text {BODPOD }}$ & $6.77 \%(5.60-7.45 ; p<0.001)$ & $\pm 3.77 \%$
\end{tabular}

424

425 Table 3. Correlations and reliability of fat-free mass measurements against the 4-component 426 model $(n=66)$.

\begin{tabular}{lccc}
\hline & $\begin{array}{c}\text { Correlation coefficient }(p- \\
\text { value })\end{array}$ & Cronbach's alfa & ICC (Cl 95\%; p-value) \\
\hline FFM $_{\text {adjusted }}$ & $0.992(p<0.001)$ & 0.996 & $0.993($ IC 95\% 0.967-0.997; $p<0.001)$ \\
FFM & & & \\
& $0.987(p<0.001)$ & 0.993 & $0.981($ IC $95 \% 0.640-0.995 ; p<0.001)$ \\
\hline
\end{tabular}




\section{$428 \quad$ Figures}

429 Figure 1. Agreement between methods. Bland and Altman plots of the difference between fat-free 430 mass (FFM) and fat mass (FM) ( $\mathrm{kg}$ ) as obtained from the BodPod assuming constant values of the FFM 431 (FFM 432 plethysmography and further corrections using adjusted density of the fat free mass) (A and C), all 433 compared to the reference method, $4 \mathrm{C}$ model (four component model).

434 Bland and Altman plots show that body composition measures derived from air displacement 435 plethysmography adjusted using the calculated density of the fat free mass have narrower limits of 436 agreement than when assuming a constant density of the fat free mass. 
A

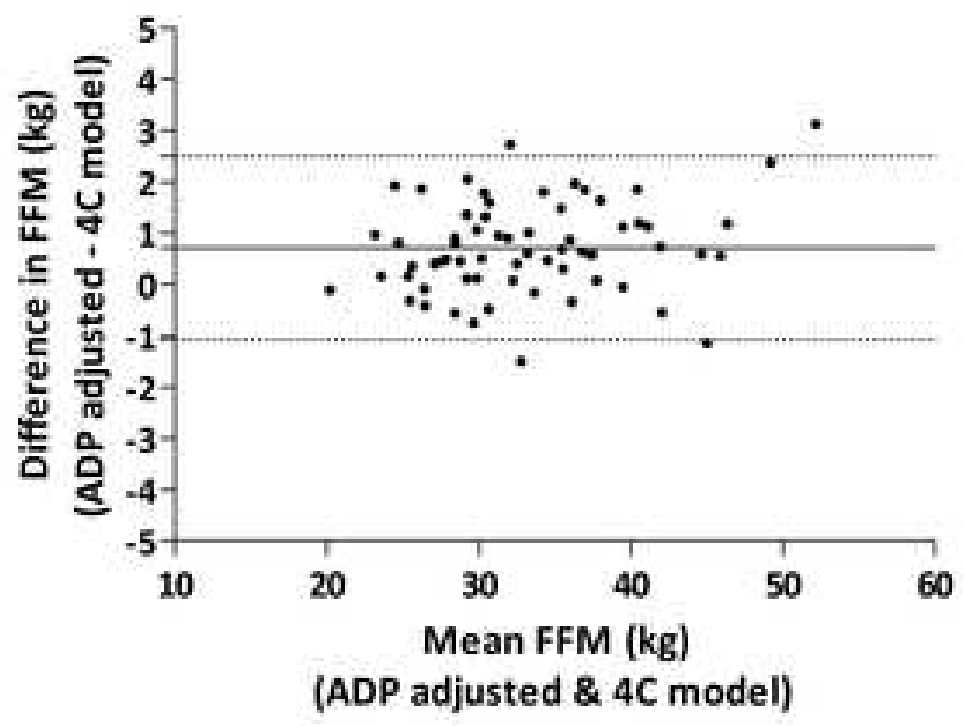

C

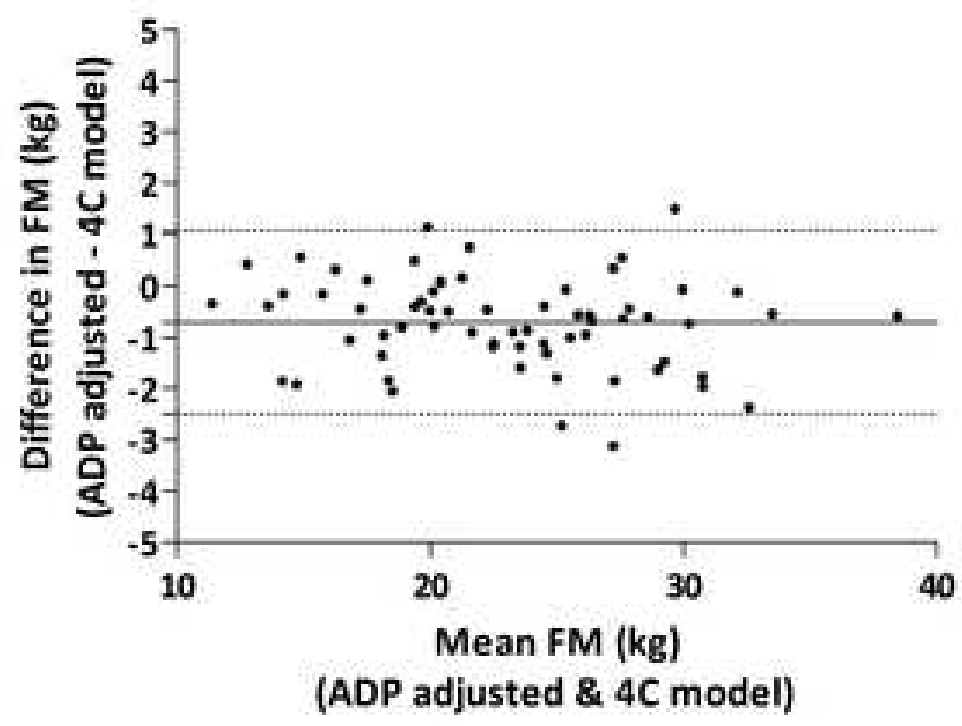

B

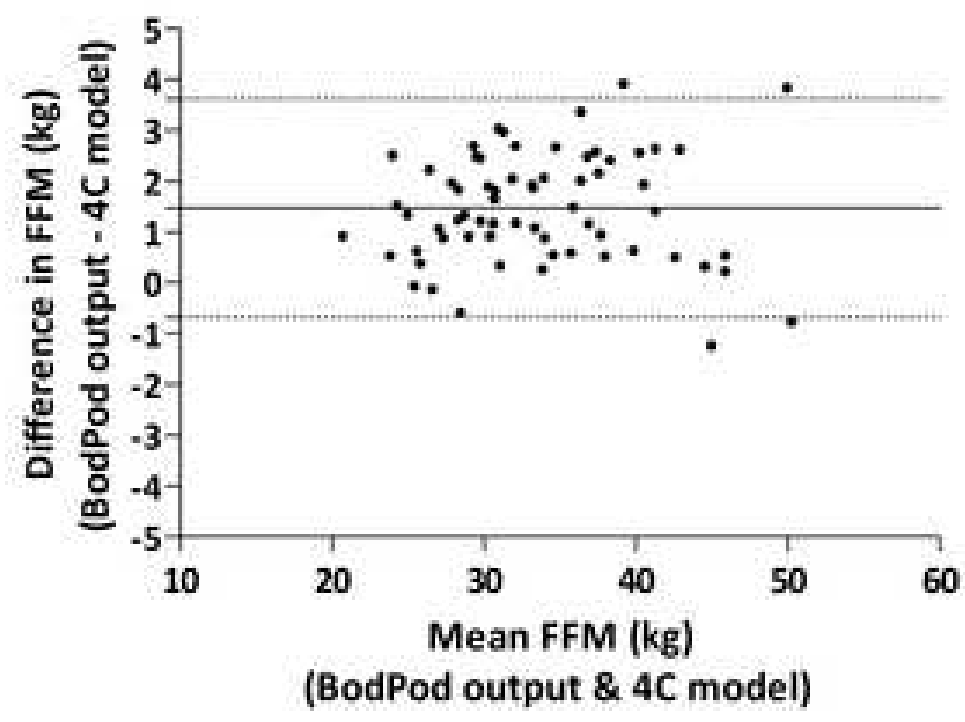

D

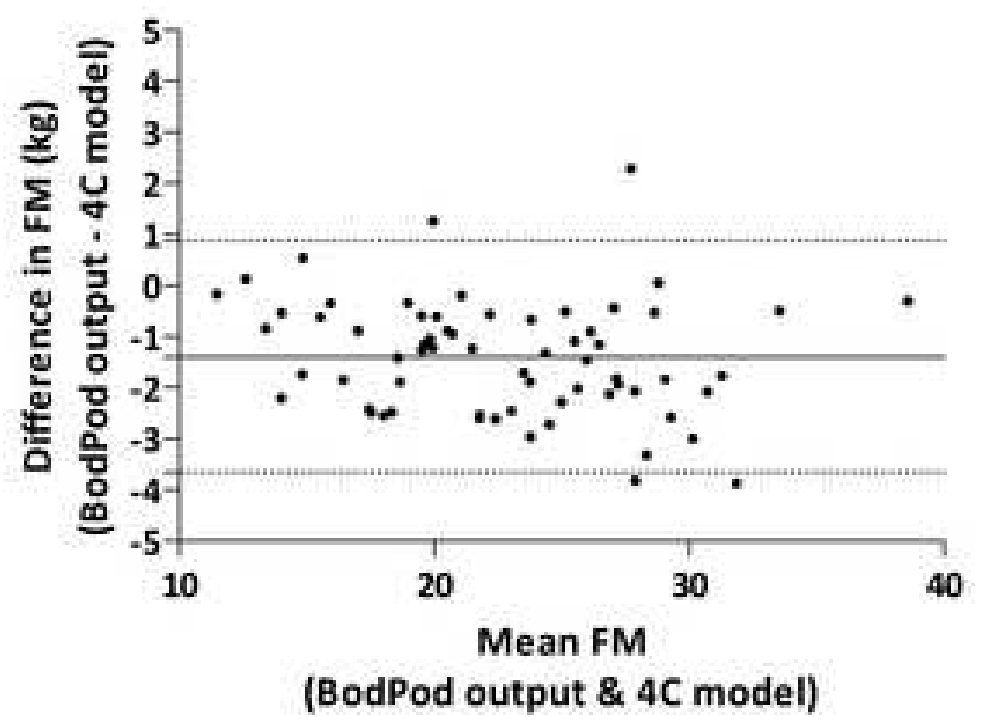


Body Composition Analysis

Adjusted fat free mass properties

in Air Displacement Plethysmography

Step 0 Complete the subjects characteristics

\begin{tabular}{|c|c|}
\hline Age (years), decimal points can be used & years \\
\hline Body weight & $k g$ \\
\hline Height & $m$ \\
\hline Add the BMI z score of the subject & $s d s$ \\
\hline Gender ( 1 if a boy, 2 if a girl) & \\
\hline Body volume (L) from BodPod & $L$ \\
\hline
\end{tabular}

Automatic calculations from that point onwards, please do not modify cells.

Step 1 Density of the fat-free mass (predicted)

$1.0791 \mathrm{~kg} / \mathrm{L}$

Step 2 C1 and C2 calculation

$$
\begin{array}{ll}
\text { C1 } & 5.4481 \\
\text { C2 } & 5.0488
\end{array}
$$

Step 3 Body Fat (\%)

$$
\begin{array}{ll}
\text { Body density } & \text { \#DIV/0! } \\
\text { Body Fat (\%) } & \text { \#DIV/0! }
\end{array}
$$

Step 4 Adjusted Fat Mass and Fat Free Mass (kg)

$$
\begin{array}{rll}
\text { Fat Mass }(\mathrm{kg}) & \text { \#DIV/0! } & \mathrm{kg} \\
\text { Fat Free Mass }(\mathrm{kg}) & \text { \#DIV/0! } & \mathrm{kg} \\
& & \\
\text { Fat Mass Index }\left(\mathrm{kg} / \mathrm{m}^{2}\right) & \text { \#DIV } / 0 ! & \mathrm{kg} / \mathrm{m}^{2} \\
\text { Fat Free Mass Index }(\mathrm{kg} / \mathrm{m} 2) & \text { \#DIV } / 0 ! & \mathrm{kg} / \mathrm{m}^{2}
\end{array}
$$

Reference: Gutiérrez-Marín D, Escribano J, Closa-Monasterolo R, Ferré N, Venables M, Singh P, Well JCK, Muñoz-Hernando J, Zaragoza-Jordana M, Gispert-Llauradó M, Rubio-Torrents C, Alcázar M, Núñez-Roig M, Monné-Gelonch R, Feliu A, Basora JM, Alejos AM, Luque V. A novel approach to assess body composition in children with obesity from density of the fat-free mass. Clin Nutr 2020. 